\title{
The Gender Equality Perception Among the Female Journalists
}

\author{
Amida Yusriana ${ }^{1}$, Sunarto $^{2}$, Nurul Hasfi ${ }^{3}$, Luz Rimban ${ }^{4}$ \\ \{amidayusriana88@gmail.com ${ }^{1}$ \} \\ Universitas Diponegoro, Indonesia ${ }^{1,2,3}$ \\ Ateneo de Manilla University, Philippines ${ }^{4}$
}

\begin{abstract}
Gender equality is mostly misunderstood as the rebellious movement by woman towards their man counterparts. Nevertheless, the effort to achieve the gender equality in every level of life has been conducted including in journalism. Journalism famously known as a man's world but nowadays, female journalists are cannot be separated from this world. This research aims to understand how the gender equality perception among the journalists in Central Java are. The theory used is Standpoint Theory by Sandra Harding and Julia T. Wood. This theory tries to see the world through woman's perspective. The method used is Focus Group Discussion. The merit of this research is served as a renewal for the gender equality perception among the society.
\end{abstract}

Keywords: Journalism, Journalists, Gender

\section{Introduction}

\subsection{Journalism is a Man's World}

Journalism is a man's world. The cause of this idea is the number of the male journalist is far higher in statistic than the woman counterparts. They dominate this field. Besides, the high mobility required by this job, the demand of time freedom and high risk form this job into more for man than for woman. This condition shows the imbalance of the number between two gender. For example, The Aliansi Jurnalis Independen (AJI) as one of the biggest communities for journalists in Indonesia are dominated by male [1].

In number perspective, female journalist is outnumbered by man journalist. The data depicts, 2 out of 10 are female journalist or 200 out of 1000 journalists are woman. The rest of the number are man. Jakarta is the only city that has the 40:60 composition for the woman compare to man. In another city, especially in the middle size city, the imbalance is clearly shown and it causes concern.

The outnumber of human resources condition influences the editorial room or even newsroom. The survey data of AJI shows that only $6 \%$ of female journalist become main editors. It means that there are $94 \%$ of the female journalist works only as reporter or have no power in decision making for editorial. The lack of female journalist in number creates lots of gender inequality in policy, including the reporter task and the problem of payment [1].

The inequality and imbalance situation that easily found in mass media field are made by the patriarchy society. It aims to preserve the male supremacy [2]. 
Up to now, media is the main tools in maintaining the patriarchy culture that harm the women [3].

Media is controlled by the man as the leader and the decision maker. According to the research conducted in United Kingdom and the Republic of Ireland stated that the decision making in the editorial room are lining to masculine type of news. The issue and topic that irrelevant for example the woman field news is considered as unimportant. Thus, the man's domination in media is still high [4].

Nevertheless, the media nowadays start to change to solve this gender inequality in journalism. This changing is not in massive scale yet but slowly people can see the change into the better. In Indonesia, only the big medias in Jakarta that starting to be more woman friendly. This changing including lactation room facility for woman. In some other media company, women are trusted to be leader, even though the number are still far less than their male counterparts.

The unideal gender equality condition in journalism rises a question for the female journalist that live inside the male's world. Since they used to live among the men, there are the possibility that their sense for woman's world is blunt. However, they do not aware about this inequality. But, is it really the case? Thus, this research aims to know how is the gender equality perception among the female journalist?

\subsection{Standpoint Theory}

This research uses Standpoint Theory to analyze the result of the study. Standpoint theory is part of critical tradition which focusing the explanation to certain group of people. Critical tradition tries in understanding the "unjustice" systems, structures in power, and beliefs system, as well as the dominate society, with certain eye of the dominant class. Critical tradition focuses in revealing the oppressive society conditions and the power structure.

Standpoint Theory as part of this tradition is created by Julia Wood and Marsha Houston. The focus is on how the environment of someone's life affect their understanding and creating their social world [5].

Standpoint theorists pressed the essence of social place because people are convinced that they are at the top are the ones who have the right of privilege to define how to be a female, male, or any other things in the given culture. Emphasize the importance of social location in this theory because they are convinced that people at the top of the societal hierarchy are the ones privileged to define what it means to be female, male, or anything else in a given culture. According to Wood and Harding that a culture is not identically experienced by everyone. Culture is hierarchically ordered so that different groups within them offer dissimilar power, opportunities, and experiences to members [6].

The main assumption of this research is that the female journalist experiences different kind of world to other women from various department. Journalism especially as the man's world will shape their understanding of gender in different spotlight rather than other women lives in completely different environment. Thus, it becomes interesting to be understood how they perceived the gender equality meaning.

\subsection{Gender Equality}

Gender roles is certain way in act for woman and man. For a man, they are asked to be masculine, meanwhile for woman asked to be feminine. 
Gender equality is the state of equal ease of access to resources and opportunities regardless of gender, including economic participation and decision-making; and the state of valuing different behaviors, aspirations and needs equally, regardless of gender.

Gender equality can be conceptualized as a problem of achieving equality as sameness (this is linked to the strategy of equal opportunities), or of affirming difference from the male norm (positive actions fit with this approach, although they are not limited to it), or of transforming all established norms and standards of what is/should be female and male (gender mainstreaming has been considered as a strategy suitable to achieve this) [7].

UNICEF has stated that gender equality means that women and men, and girls and boys, gets the same rights, resources, opportunities and protections. It does not require that girls and boys, or women and men, be the same, or that they be treated exactly alike [8].

The extreme gender neutrality can create a getting worse condition for women, it is because the law concludes that women are in the same condition to men. It ignores the biological fact which the process of reproduction and pregnancy has no equality, and that distinguished from the physical differences there are inferior position to women - a situation which requires a certain approach socially and culturally [9].

Gender equality in fact involving the stereotype concept. Masculine and Feminine gender roles are often perceived in terms of opposites. If a man is considered to be independent, for example, a woman is seen as dependent. The sexes were described in opposites ways whether the respondents listed their own beliefs about male and female traits or checked these traits on a list that was given to them. However, studies done to see which traits men and women actually do possess do not show pattern of opposites. In reality, men and women overlap in regard to many characteristics. For example, some men and women are competitive, and some men and some women are nurturant. There is also a great deal of variation within each sex in terms of the degree to which trait is evidence [10].

Based on thus explanation, gender equality is giving the same opportunity, experience and life condition to man and woman without seeing their sex. But at the same time people need to be aware that equality cannot be understood as exact same $100 \%$, because naturally man and woman different. What should be avoided is asked them to fill certain roles. Woman have the ability to labor, thus their body anatomy cannot keep up to man. To ask them live like a man is not what gender equality's goal Instead, let every man and woman live according to their own individual traits.

\section{Methods}

This research uses the qualitative approach as the method. The nature comes from the research question. It seeks for people's insight about a phenomenon among the journalists. Thus, to get the correct and broader answer, Focus Group Discussion (FGD) is chosen to be the method in collecting the data.

\subsection{Focus Group Discussion}

Focus group discussion is a technique emerged as a qualitative data collection approach and a bridging strategy for scientific research and local knowledge [11]. 
The original founder of focus group was sociology field. However recently, focus group is excessively used in the marketing field, and also, it has been gaining popularity in another field. In social studies, Robert Merton had published the first work using focus group.

Focus group is a condition which the interview is in depth and organized in a group. The meetings present characteristics according to the proposal, size, composition, and interview steps by steps. The focus or object of analysis is the interaction within the group. The interviewees influence each other by their answers to the main ideas and contributions within the discussion [12].

A focus group discussion is a form of group interview as a smaller group form. It consists of people and lead by a moderator. In general, the rules to control are loose and weak. It can discuss various kind of topic. Focus group has general characteristic as a very homogeneous group. There are time division in each session and data qualitative collection that focused on topic. The three phases in focus group discussion are planning, conducting interview and analysis [13].

One merit of comparing focus groups discussion to any other methods is a more current understanding of the strengths and weaknesses of the focus groups discussion. For instance, rather than just lining exploratory research as a strength of focus groups discussion, now it is more necessary to note that personal nominal interviews can be a more effective as a technique for idea generation. Morgan and Krueger [14] also stated that the benefit of focus groups discussion for investigating complex behaviors and motivations were producing a direct result of the conversation within focus groups, what has been termed as "the group effect" [15][16]. A strengthened on the specific style of interactions that happen in focus groups discussion is also an increase over vague assertions is one of the strengths. Things make the discussion in focus groups more than the sum of separately personal interviews is the data that the participants both inquiry one to another other and explain themselves to each other. As Morgan and Krueger [14] have also emphasized, such interaction offers valuable data on the extent of consensus and diversity among the participants. This ability to observe the extent and nature of interviewees' agreement and disagreement is a unique strength of focus groups. A further advantage comes from the interviewer's ability in questioning the interviewee for comparing among their experiences and views, rather than aggregating individual data in order to speculate about whether or why the interviewees differ [12].

\subsection{FGD Technique}

For conducting the focus group discussion, Morgan stated to determine the sampling, group number and moderator as the initial stage [12]. This research invited ten people as the interviewee consist of journalists from various media such as Jateng Pos, BBC Indonesia, SM Online, Suara Merdeka and Cakra TV. Focus Group Discussion was conducted in May $30^{\text {th }}$ at 11.00 am to $1.00 \mathrm{pm}$. Started by delivering the analysis of writers. Mr. Sunarto by his research about the gender construction in Media, Female journalists by Nurul Hasfi and Women's Friendly Media by Amida Yusriana.

The analysis presentations tried to give the frame of references for interviewee. Thus, we are on the same understanding of topic. Moreover, to present the fact of how far the media has been taking action towards gender equality up to now. The analysis presentation is the first session followed by opinion disclosure by each interviewee. Among 10 of this group, 5 are women and 5 are man. Every interviewee got the same amount of time. Ten minutes for each person. The moderator is one of the communication science lecturers, thus he is capable in bringing out this kind of topic. 
Unlike the conventional and normal focus group discussion. Covid-19 has caused this FGD to be held by online media. We used the Microsoft Teams as media to interact during FGD. The next step after is to transcript the result of FGD to be able to answer the research question.

For this research, since we will use the Standpoint Theory, the interviewee will be deducted only the women ( 5 persons).

\section{Result and Discussion}

How the perception about gender equality among female journalists become a very interesting topic to be discussed because of the phenomenon of living in the man's world. In addition, up to now the gender equality has not change much in the editorial room. One of the causes is because the leadership always handled by man. The leadership lead to the decisionmaking ownership is in man's hand. If the owner is dominated by man then the woman's need cannot be heard or even voiced. This causes the gender equality develops in rather slow motion in journalism world.

Gender equality become one of the most important issues in Gender studies. It defines equal roles between man and woman, in which in society both genders have been defined differently as masculine for man who is more dominant than the feminine (woman).

Titterington [17] mentioned that the principal of gender equality guaranteed in a genderneutral laws that possible participation in all the economic, educational and political and other arenas of community. The laws reject all kind of discriminatory behaviour against women and any kind of activities associated women as an inferior member of society. This, finally woman equality has main aim to improve woman in society.

There are many studies conducted for exploring gender equality in many human aspect from politic, arts, media, economic, etc. McClain and Linda [18] explore about some dimensions of woman equality in politic particularly citizenship and relate the discussion from the lens of human right.

Meanwhile, Lourenço [19] explore the prospect of media organization, CSO, policy maker make articulation with education institution to achieve gender equality. UNESCO as international organization is defined as institution that have role in initiating the program. Although this study also concerns on the role of mass media organization in achieving gender equality in society. However, Lourenço [19] does not see journalism/ media owners training of gender equality issue is a sufficient step to gain women empowerment in the media. She said that self-regulation and internal media policy as well as national policies support gender sensitive media are more effective in developing sustainable change.

Another gender studies focusing on the issue of gender equality done by Medalia and Chang [20] who examine the correlation between the gender equality and the sex gap in mortality. This study assessing 131 countries both Less Developed Countries (LDCs) and Highly Developed Countries (HDCs). She found that the influence of gender equality is conditional in the level of development.

This article gives a new setting on a persistent topic, that is conducted in 4.0 era and in a local media. There are also limited studies concern about gender equality in media in Indonesian context. The most comprehensive study explore about woman equality in journalism in Indonesia is done by Luviana [1]. Luviana give complete description about the law quality of gender equality in Indonesian media by focusing on the indicator of female journalist participation in newsroom, female journalist roles in newsroom as well as in the professional organization and media organization' treatment to female journalist. While the study is focusing 
on the external indicator for assessing woman equality, this article tries to capture the internal factor of the female journalist by trying to explore their perception of gender equality in her media practice as well as their awareness about the issue.

By employing the standpoint theory, this research tries to understand how female journalists have different kind of life compare to woman in other job. Because the Standpoint Theory tries to give space to the minority in voicing their experience that hard to be articulated. Firstly, we asked about their perception being a female journalist. Here are the statements within the discussion:

What is their perception of being a female journalist?

1. There is nothing impossible for woman even though we have to do the exact same thing to man.

2. I have been taught to be as strong as a man or it is just my own feeling that find no problem to be treated equally to man.

3. In fact, when we conducted the news gathering, between man and woman had no bias, we agreed to work cooperatively.

4. Because for me, journalist is a journalist, there is no sex difference in journalist.

5. I used to go to out of town for reporting and taught to be as strong as steel.

Based on the focus group discussion conducted, we found that among the woman participated, all of them addressed the gender equality terms in a negative tone. This conclusion comes out by the words they use to describe such as:

Negative Tone in Gender equality Concept

1. "As the time goes by, the gender issue is gaining more popularity, there are some side that got weakened by this. For me, as a woman, I feel weakened. I am not as strong as before".

2. "This job is labelled as man's job. Everyone was positioned as man and the right were the same. Nah, I feel this was a good approach because we became so strong, even in the field during reporting".

3. "Then the awareness (of gender equality) arose from the women. In fact, when we conducted field report, between man and woman had no bias, we agreed to work cooperatively. But then since the biases arose (gender equality), our heart notice those biases unconsciously".

4. "As a female journalist, I never try to ask certain privilege as a woman, because I will be trapped into masculinity scope. Because for me, journalist is a journalist, there is no sex difference in journalist, this is the value that I always rooted inside as a journalist".

5. "When I was in Tempo, I've taught to be equal to man, I used to go to out of town for reporting and taught to be as strong as steel".

Based on those responses, five of interviewee conclude rather negatively towards how the gender equality concept came into journalism world. They feel weakened, because they used to live to be the exactly same to their man counterparts. Meanwhile, in gender equality stated that the extreme gender neutrality can create a getting worse condition for women, it is because the law concludes that women are in the same condition to men. It ignores the biological fact which the process of reproduction and pregnancy has no equality, and that distinguished from the physical differences there are inferior position to women - a situation which requires a certain approach socially and culturally [9].

Gender equality tries to bridge this understanding that man and woman are different because of their body anatomy. The equality should be understood as specific approach according to the differences. 
However, the interviewee think that they are as strong as man and they are proud of this fact. However, this strong thought has been growing as the result of media policy and environment since they start their career as journalist. Here are the statements:

How can this perception grow?

1. I work in Jateng Pos since 2002, during that time, I felt that man is dominant, but since then I started to feel happy, so I kept up with the flow

2. So then in my opinion, media is actually gender friendly already. Maybe since I have been taught to be as strong as a man or it is just my own feeling that find no problem to be treated equal to man

3. In the working place, the mechanism or the working system makes me cannot distinguish the differences between man and woman

4. When I was in Tempo, I've taught to be equal to man, I used to go to out of town for reporting and taught to be as strong as steel

Four out of five our interviewee was taught to work like a man, to be a man, as strong as a man. This understanding about woman is same in treatment as a man is wrong. Because of this deep-rooted teaching method in journalism to female journalist, they are failed to see the real meaning of gender equality and then to see gender equality issue as a problem. Some statements also show their unhappy feeling because of gender equality issue. Most of them are senior journalists who have been working in the field for years. So, they experienced before and after the gender equality issue arose among people. The reason behind of the unhappiness are feeling weakened, they used to hardship. However, they tend to associate gender equality to convenience and privilege.

Those are unmatched according to the real aim of gender equality issue. People tend to think that gender equality is only for woman, meanwhile man also the parts of disadvantage group for this patriarchy situation. The stereotype aspect is the strongest concept to be adopted by man and woman for their whole life. By adapting gender equality means that both genders can live freely according to their original characters. Man should not need to be always strong and woman should not be vulnerable every time. Man and woman are diverse in characters. Gender equality concept aims to set people free from those roles. But unfortunately, this concept is misunderstood by female journalist.

\section{Conclusions}

Using Standpoint Theory, this research can give a chance to hear the female journalist's perspective about gender equality. Their life among man in the journalism have been building certain perspective about gender equality issue in their working place.

The long adaptation and teaching period during pre-gender equality awareness have built negative and unhappy feeling for this issue. In their mind, gender equality issue only weakened the woman and put them in privilege. In conclusion, the female journalist is failed to see the real meaning of gender equality.

\section{References}

[1] Luviana, Jejak jurnalis perempuan: pemetaan kondisi kerja jurnalis perempuan di Indonesia. Jakarta: Aliansi Jurnalis Independen, 2012.

[2] M. Hidajadi, "Hubungan Ibu dan Anak Perempuan: Sebuah Distorsi?," J. Peremp., vol. 16, pp. $7-15,2003$. 
[3] Y. Stellarosa and M. W. Silaban, "Perempuan, media dan profesi jurnalis," J. Kaji. Komun., vol. 7, no. 1, pp. 97-109, 2019.

[4] K. Ross and C. Carter, "Women and news: A long and winding road," Media, Cult. Soc., vol. 33, no. 8, pp. 1148-1165, 2011.

[5] S. W. Littlejohn and K. A. Foss, Theories of human communication. Waveland press, 2010.

[6] E. A. Griffin, A first look at communication theory. McGraw-Hill, 2003.

[7] M. Verloo, Multiple meanings of gender equality: A critical frame analysis of gender policies in Europe. Central European University Press, 2007.

[8] UNICEF, "Promoting Gender Equality: An Equity-Focused Approach to Programming," in World Health Organisation, 2011.

[9] F. Raday, "Gender and democratic citizenship: The impact of CEDAW," Int. J. Const. Law, vol. 10, no. 2, pp. 512-530, 2012.

[10] M. Richmond-Abbott, Masculine and feminine: Gender roles over the life cycle. McGraw-Hill College, 1992.

[11] T. Nyumba, K. Wilson, C. J. Derrick, and N. Mukherjee, "The use of focus group discussion methodology: insights from two decades of application in conservation. Methods Ecol Evol 9 (1): 20-32." 2018.

[12] D. L. Morgan, Focus groups as qualitative research, vol. 16. Sage publications, 1996.

[13] L. Mishra, "Focus group discussion in qualitative research," TechnoLearn An Int. J. Educ. Technol., vol. 6, no. 1, pp. 1-5, 2016.

[14] D. L. Morgan and R. A. Krueger, "When to use focus groups and why," Success. Focus groups Adv. state art, vol. 1, pp. 3-19, 1993.

[15] M. A. Carey, "The group effect in focus groups: Planning, implementing, and interpreting focus group research," Crit. issues Qual. Res. methods, vol. 225, p. 41, 1994.

[16] M. A. Carey and M. W. Smith, "Capturing the group effect in focus groups: A special concern in analysis," Qual. Health Res., vol. 4, no. 1, pp. 123-127, 1994.

[17] L. M. Vieraitis, S. Britto, and R. G. Morris, "Assessing the impact of changes in gender equality on female homicide victimization: 1980-2000," Crime Delinq., vol. 61, no. 3, pp. 428-453, 2015.

[18] J. L. G. McClain, Linda C, Gender Equality: Dimention of Women's Equal Citizenship. Cambridge University Press, 2009.

[19] M. E. Lourenço, "Gender equality in media content and operations: articulating academic studies and policy-a presentation,”Stud. High. Educ., vol. 41, no. 5, pp. 927-931, 2016.

[20] C. Medalia and V. W. Chang, "Gender equality, development, and cross-national sex gaps in life expectancy,” Int. J. Comp. Sociol., vol. 52, no. 5, pp. 371-389, 2011. 